\title{
Entering the Field
}

\begin{abstract}
In this chapter, we deal with authoritarian field research in relation to ethics procedures (or lack thereof!), visas, and permits, and what we do in advance to prepare for an optimal, and optimally safe, fieldwork period. We acknowledge that fieldwork in authoritarian contexts is mostly not very dangerous for researchers, but it can be. We discuss the particular nature of authoritarian fieldwork risks, the concrete risks we ourselves and others have faced, and what we can do to assess and mitigate those risks. We conclude that while we should be aware of risk and try to minimize it, we need to accept that risk cannot be eliminated if we want to engage in authoritarian fieldwork.
\end{abstract}

Keywords Authoritarianism • Field research • Risk • Fieldwork ethics - Safety $\bullet$ Access

In this chapter, we discuss our preparations for entering the field and our handling of the risks associated with authoritarian fieldwork. In terms of preparations, we deal with experiences with the ethics procedures (or lack thereof!) of universities and funders, the vagaries of visa requirements, and what we do in advance to prepare for an optimal, and optimally safe, fieldwork period. We discuss the particular nature of authoritarian fieldwork risks, the concrete risks we ourselves and others have faced, and what we 
can do to assess and mitigate those risks. We will conclude that while we should be aware of risk and try to minimize it, we need to accept that it cannot be eliminated if we want to engage in authoritarian fieldwork.

\section{ETHics Procedures}

Authoritarian field research poses a number of ethical challenges. The most prominent of these is undoubtedly the potential risk to our respondents, but risk to ourselves, issues of informed consent, and potential misuse of findings by authoritarian regimes are also among them. We deal with such issues, and with what we hold to constitute ethical behavior, throughout this book. But we also operate in institutional environments, which sometimes come with their own ethical review procedures. We have found great variance in the appropriateness and comprehensiveness of such procedures. We recognize a general reflex among academics to consider ethical review as just another bureaucratic nuisance. However, it is our shared experience that, when well-designed, ethical reviews can be extremely useful in pushing us to reflect on ethical implications of our research. Our Kazakhstan researcher, for instance, asked colleagues who had done fieldwork research in Central Asia before what they had done to keep interview material confidential, and whether they had trained research assistants on ethical matters, in order to meet the ethics requirements of her co-author's US university, which funded the research. She would never have asked colleagues these questions if the Internal Review Board's questions had not required her to describe the procedures she would use. We also have some experience with less appropriate ethical review procedures, and considerable experience with a complete absence of ethical review procedures.

We have on occasion experienced ethical review as a bureaucratic nuisance ourselves: our current funder, the European Research Council (ERC), for instance insisted, after most of the fieldwork had already taken place, on receiving a copy of the interview protocols of each our field researchers. We dutifully supplied sample protocols for each researcher, but we do not believe these to be particularly meaningful. As every qualitative researcher knows, every interview is slightly different from the last, and we never stick precisely to the script. We also have some doubt as to whether the ethics auditors who asked for the interview guides actually went on to peruse them. This example, we would put in the category of harmless bureaucratic nuisance: we do not think the request was particularly 
useful, but it did not cost us a huge amount of time, and it did not in any way interfere with our own views of what is ethical.

Ethical review procedures can become really problematic, however, when their existence actually causes us to behave less ethically than we otherwise would. This can come about in response to 'one-size-fits-all' procedures, without an understanding of the particularities of qualitative social science research in general, or of the specific challenges of authoritarian field research. Much depends on who conducts the review. Thus, our funder, the ERC, uses a form that asks whether 'the proposal meets the national legal and ethical requirements of the country where the research will be performed' and whether 'approval of the proposed study by a relevant authority at national level' will be sought. Fortunately, our ethical auditors ticked both boxes as 'yes', while indicating in writing their acceptance of our explanations why we could not guarantee to always be in compliance with national law, or get formal approval from state authorities (see also below). They also accepted our argument that under the circumstances, oral consent was more appropriate than signatures on consent forms (see also Wall and Overton 2006, 64). Had the ethics review been conducted by someone with less understanding of the particularities of authoritarianism research, we might have had difficulties getting clearance. We do not know of any instances where an ethical review procedure actually prohibited a scholar from undertaking authoritarian field research (but see Matelski 2014, who mentions a case relating to Myanmar). A more frequently encountered problem is that, by making impossible requests, review boards may actually 'encourage obfuscation' rather than transparency (Wall and Overton 2006, 62). We know of a colleague working in African contexts for instance, who had been taught by his wellrespected $\mathrm{PhD}$ supervisor to produce counterfeit informed consent forms, because their university required them, even in contexts where they would be quite inappropriate and perhaps even unethical.

While we have no personal experience of ethical reviews making impossible demands, we have considerable experience of operating in universities that have no ethical review procedures whatsoever. Three of the four postdoctoral researchers in our project encountered neither ethics procedures nor any ethics training during their PhD trajectory. Our Morocco researcher went on to work for two other European universities without encountering any institutional engagement with research ethics. The researchers in question do not believe they have made fatal ethical mistakes in their research, but the lack of institutional awareness of ethical 
concerns did sometimes make them feel unprepared for problems and dilemmas they encountered in the field. Moreover, it meant that there was no obvious person or body to consult on these matters; they were left to figure them out on their own, without much experience.

In general then, we would argue for engaged ethics procedures, preferably with an element of human interaction, that force us to reflect on ethical challenges we might encounter without turning into a bureaucratic box-ticking exercise. We would urge academics to push for such procedures, not only when they face procedures that are too rigid but also where they encounter an absence of either training or clearance reviews.

\section{Gaining Entry: Permits and Visas}

As part of the ethics procedures described above, some universities and grant-making institutions insist that researchers should seek prior permission to do research from some authority in the country where their fieldwork is to take place. There may, in general, be circumstances in which requiring such permission is quite justified, for instance, when doing research related to a country's natural resources or conducting medical trials. When it comes to the social sciences, we believe that there is no general justifiable need for such permission, but there may be circumstances in which it is reasonable for the state to limit entry. Loyle (2016, 927), for instance, describes how Rwanda instituted a permit system 'in part as a response to rampant and unchecked social and scientific research that was conducted in the country post-1994 with limited regard for the health and psychological well-being of research participants'. Today however, Loyle points out, the 'process serves as a high-cost barrier to research in Rwanda', and severely constrains research on subjects of sensitivity to the government.

Below we describe some of our own practices when gaining entry, and the restrictions and ambiguities in state policies on permission for research we encountered. With one exception, none of us have ever sought government permission for our research on authoritarianism, or applied for a research visa. Such an official request, if there is even a dedicated procedure to process it, would only serve to attract the authorities' attention to our research, arouse suspicion, and most likely result in a denial. For Morocco, for instance, there is a procedure, and one is formally required to ask for permission to do research in the country. But getting permission can take months and sometimes it is just not given. To our knowledge, 
most Maghreb researchers do not apply for it. India officially requires a research visa, but despite being formally democratic, it is very restrictive in giving out visas for any politically sensitive research, such as in our case repression in the context of subnational authoritarianism, but also, for instance, on the Maoist insurgency or other armed groups, or any research on Kashmir.

Our first visit to the field was often different from subsequent experiences in terms of our purpose for going. Our Iran researcher came primarily to study the language, our Kazakhstan researcher was working for an international organization, and our India researcher felt that, as a master student, the line between just 'hanging out' as someone who is interested in the country and being there as an academic researcher was still quite fluid. Once we were set on our career course, this kind of convenient ambiguity has tended to dissipate. Even our China researcher, a Chinese national who grew up in the country, now clearly goes as a researcher, not just someone visiting home.

So, how do we enter the country nowadays? Sometimes, we go on tourist visa. Tourist-friendly countries like Malaysia, Morocco, or Mexico make it very easy to enter the country-indeed Europeans can stay in Morocco for three months without even applying for a visa. There is something uneasy about doing research on a tourist visa or without a permit, especially where a research visa or permit does in fact exist. But a tourist visa does not imply that we are treating the purpose of our presence as a secret. We all carry letters from our home universities, signed by a head of department or university official, explaining our research, but we have rarely had occasion to produce them. Our Morocco researcher writes 'study, work and tourism' or 'work and tourism' on her immigration form. Our India and Mexico researcher has conducted interviews with local policemen and magistrates while on a tourist visa. The experience is that state officials are not in the habit of questioning whether one has a research visa or permit: how you came into the country is not really their concern. Nonetheless, the lack of an official stamp of approval can make us vulnerable, or at least make us feel vulnerable. Our Morocco researcher applied for official approval for her research on Salafists after experiencing intrusive surveillance, an experience detailed in Chap. 5. She applied not because she expected to get permission (and indeed she never received a response to the request) but simply in order to signal that she was not doing clandestine research. 
For other countries, such as China, Iran, or Kazakhstan, getting any type of visa requires more bureaucratic effort, and moreover, there is a realistic risk of being denied entry. To some of us, the restrictive visa policies seem like part and parcel of the system of authoritarian control: the government wants to strictly monitor who enters, and who does what in the country. In post-Soviet countries in particular, it is not just the entry visa. One needs to regularly register one's exact whereabouts, with a hotel or with the migration police. Having said that, as western researchers we may too easily read authoritarianism into such requirements, and forget the often draconian procedures of our own authorities vis-à-vis non-residents. Our China researcher, when she first came to the United Kingdom from China, also had to register with the local authorities at the police station.

An important commonality in our experiences with gaining entry is ambiguity: the rules are unclear, they keep changing, or they are applied unevenly. Our Iran researcher is pretty certain that the lack of response to his request for a study visa in 2015 was not politically motivated, but just a matter of sloppiness, the application had been delayed or forgotten somewhere, and he was quickly issued a tourist visa instead. At the same time, Iran researchers do regularly have their visa denied on what are likely to be political grounds. Even some researchers with long-term relationships and networks have still been denied. Our China researcher can freely leave and enter the country, but she has seen that the treatment of foreign scholars by the Chinese government appears quite arbitrary: a colleague whose visa application was rejected reapplied two weeks later and was accepted. A US-based scholar working on Tibet was rejected, which seems unsurprising in itself, but then another researcher working on the same topic was accepted at almost the same time. In Kazakhstan, entry has actually become easier in recent years, with visa-free regimes offered for short stays. But the bottom line, in Kazakhstan as in other authoritarian contexts, is that the bureaucratic requirements are never quite stable and transparent, and this in itself creates the kind of legal uncertainty that appears to be one of the hallmarks of authoritarian rule. Most authoritarianism scholars gain access to their fieldwork sites most of the time, but denial of entry is always a possibility, and even expulsion is never unthinkable.

\section{Constrained Choices}

Our choices of fieldwork countries, and of research topics, are in part determined by what is possible, and safe. Little is in fact known about what drives fieldwork choices. Clark's (2006) valuable survey of difficulties 
faced by researchers in the Middle East and North Africa only showed 16\% of respondents specifying 'the political situation' and safety as contributing to their country choices, and did not distinguish between repression and other safety risks. A more recent study on the political risks of field research in Central Asia found that '(s)everal respondents reported that they no longer work in Uzbekistan' and a 'few respondents singled out Turkmenistan and Azerbaijan as sites where they have experienced significant censorship/restrictions, chosen not to go, or experienced difficulty going'(CESS 2016, 7). Goode (2010) initially discerned a relation between Russia becoming more autocratic and a decline in fieldwork, but qualified his conclusions in a later study of the broader region (Goode 2016). Nonetheless, we would logically expect the most repressive regimes within the authoritarian universe to be less likely settings for field research: either because it would be too dangerous, or simply because it is impossible to gain access. Similarly, assessments of feasibility and risk are likely to constrain the choice of research topics and research questions. We do not expand on this point, since it has been dealt with extensively by the contributions to Observing Autocracies from the Ground Floor (Goode and Ahram 2016). At the level of our own considerations and observations of colleagues, the notion of constrained country choices, and associated knowledge gaps, seems to have validity. Our Kazakhstan researcher for instance made a clear choice, within Central Asia, not to do research in Uzbekistan for safety reasons. We know no one who has done fieldwork in Saudi Arabia, Turkmenistan, or North Korea. We know colleagues who have started doing research in Myanmar only after it democratized from 2011. And more dramatically, we know many colleagues who have abruptly stopped doing research in Egypt when it became much more repressive in recent years.

\section{Not So Dangerous}

Field research in authoritarian settings is by no means the most dangerous kind of social science research one can imagine. Research on organized crime, or in the middle of civil war, is likely to be more dangerous. The risks that a foreign academic runs in an authoritarian country are also incomparable to the risks run by local activists, because of both components, 'foreign' and 'academic'. We write academic books and journals, the tone is balanced, the jargon complex. We do not usually express outrage in our academic work. Moreover, more often than not, we write in 
English and not in a local language that is easily accessible to the population. Both foreign journalists and local academics are typically more at risk than we are. A different matter is the risk we may pose to our respondents, an issue we consider in more depth in Chaps. 4 and 6.

Gentile distinguishes between two types of security risk in authoritarian contexts: "crime-related risks, [in which] the state is, or at least should be, your "friend" and 'risks in which the state (the secret services, internal security forces and the like) is your "enemy" (Gentile 2013, 427). We would add two further categories: risks resulting from crisis situations and risks that are related to the authoritarian contexts in more indirect or ambiguous ways. We do not discuss the first type of risk, which does not specifically relate to our position as researchers in the authoritarian field. Along with all other preparations, researchers should of course make themselves aware of the crime profile of the places where they are to do research and take relevant precautions. We devote most attention to the first, 'classic authoritarian' type of risk, but will also address 'crisis risk' and 'indirect risk'.

Depending on which county one investigates, and especially which topic, a researcher may need to prepare for being under electronic or physical surveillance (see also Chap. 5), for being interviewed by security agents (see Gentile 2013), and for being warned off certain activities or topics. All these things have happened to us. It is rare for a researcher to be arrested, detained, or expelled, and slightly less rare but still unusual to be denied entry. These things have not happened to us. Clark's (2006) survey, mentioned above, despite the modest number of responses (55) gives some insight into the frequency of such events, at least in the Middle East and North Africa: '22\% of the researchers noted that they at one point had difficulties gaining entry to the countries of research or obtaining research visas due to the perceived political sensitivity of their topics by the host governments. Others reported that they had experienced the threat or actual seizure of their research data (5\%), surveillance and monitoring by security (4\%), arrest and/or detention (4\%), and police harassment $(2 \%)^{\prime}$. The recent Central Asia survey, without giving exact percentages, similarly reports 'ten first-hand accounts of arrest and detention by state officials and a further seventeen of various forms of harassment of the researcher or assistants' among a few hundred respondents (CESS 2016, 8).

Ahram and Goode $(2016,839)$ discuss the case of 13 China scholars who were denied visas after publishing a book on Xinjiang province, as 
well as the arrest of Alexander Sodiqov, a PhD student who was arrested on suspicion of treason and held for over a month in Tajikistan (Goode and Ahram 2016, 828). Another incident that has attracted much attention is that of the immediate expulsion of Davenport and Stam (2009) from Rwanda after presenting findings on the genocide that were uncomfortable to the government. There have also been a few recent cases of expulsion of Russia scholars, specifically those who study archives, but according to the US embassy in Moscow, the incidents concern a 'very small minority of the large number of Western academics who travel and study in Russia' (Schreck 2015). While it is difficult to generalize about visa denials, expulsion remains a matter of relative rarity, and arrest even more so, in most authoritarian contexts.

\section{And Yet It Can Be Dangerous}

There have been some very worrying recent cases of arrest and detention of social scientists in Iran. Homa Hoodfar, an anthropologist, was held for almost four months and then released in 2016. She coped with prison brutality by dealing with the situation as unintended 'fieldwork' (Kassam 2016). Most recently and dramatically, Xiyue Wang, a PhD student in history at Princeton University, was sentenced to ten years' imprisonment on charges of spying after having already spent a year in prison (Gladstone 2017).

So far, we have not distinguished between foreign visitors such as Davenport and Stam, and dual nationals or nationals investigating their own country, such as Sodiqov or Hoodfar. Since we are dealing with rare occurrences, we cannot systematically compare, but it seems likely that the latter two groups and especially nationals are likely to be more vulnerable to the risks we have outlined, since their treatment is less likely to lead to diplomatic intervention, even though their home university might exert itself on their behalf. Moreover, even apart from the risk of arrest, the impact of expulsion or visa denial on them may be much greater, entailing not just an enforced change of country specialism but being cut off from homeland and loved ones. As for local academics, they fall into a different category altogether, which is not the subject of this book. For them, many research topics are likely to be proscribed, and in most cases, research on their country's authoritarian system as such will not be possible.

The death of Giulio Regeni, a PhD student at the University of Cambridge who was tortured to death whilst doing fieldwork on trade unionism in Egypt in 2016, sent shockwaves through our community of researchers. It 
was one of the reasons that propelled us to write this book. He was killed for doing exactly what we do. Contrary to some portrayals in the press, Regeni was neither a clueless student, nor did he have a subversive political agenda. He was in close touch with academics who had tremendous local knowledge and made no obvious mistakes. Regeni became the victim of a rapidly deteriorating situation, in which mid-level security agents may have had, or seized, more autonomy than is usual in authoritarian settings. Regeni's death and the responses to it highlight the rarity of such an extreme act of repression against a foreign scholar, and reminds us of our relative safety in comparison to our respondents in the countries we study. Generally, it continues to be true that it is a terrible publicity for a regime to harm a researcher from a western university, and therefore highly unlikely. But Regeni's death is also a reminder that in doing authoritarian field research, we must accept a small risk that things go horribly wrong. The likelihood of such incidents is very low when the regime is stable, but increases in crisis times when the regime feels threatened and needs to reassert its power, such as in the aftermath of the Arab revolts, the Iranian Green Movement protests, or the Andijan massacre in Uzbekistan. Of course if we can predict looming periods of instability in advance, we may (despite the fascination such periods hold for us as political scientists) opt to refrain from doing fieldwork at such times. But one of the hallmarks of authoritarian rule is its apparent unassailability, sometimes followed by sudden collapse, and scholars have had notorious difficulty predicting such collapse. So, we must accept the chance of unexpected crises, and concomitant uncharacteristic behavior from state agents, as one of the known unknowns associated with authoritarian field research.

Possibly the most dangerous work within our group was carried out within an ostensibly democratic context (at least at the national level): in Veracruz, Mexico. The research focused on the subnational authoritarian rule of this region, and in particular on the repression of critical journalists, several of whom had been found murdered in the previous years. The risks he anticipated were only in part connected to the subnational authoritarian context and the researcher's plans. A white young man could be taken for an oil executive (lucrative for kidnapping purposes), or, more connected to politically sensitive interviewing, for a US Drug Enforcement Agency (DEA) official. An important generalizable point here is that there is no obvious correlation (nor, we hasten to add, an inverse correlation) between how authoritarian a state or regional context is and how vulnerable a researcher may be to criminal violence. 


\section{Assessing Risk in Advance}

One obvious source of information in preparing for fieldwork in authoritarian contexts is human rights reports, or conversations with human rights activists. A problem with this kind of information, however, is that it reports on only one dimension of a multidimensional political system: its human rights record. The purpose of human rights reports is not to give a would-be researcher a balanced and personalized sense of risk. It is important for researchers to know about censorship and about dissidents in prison but also to get past identifying a regime solely with its censors and prisons, especially when their research questions focus on issues other than repression. When a human rights organization uses an expression like 'culture of fear', for instance, we should take it seriously, but not assume a priori that we will indeed find all our potential respondents terrified. Only particular groups will come in for harsh repression, and our likely respondents may not belong to such groups. As Pepinsky has written about Malaysia, in many contexts, '( $m$ )ost not-very-vocal critics will live their lives completely unmolested by the security forces', and will find living under authoritarianism 'tolerable' (Pepinsky 2017).

A similar caveat should be made about the security briefings of our foreign ministries. They are typically written with tourists, perhaps businesspeople in mind, and tend to err on the side of caution in case of any political instability. At the same time, they are not geared towards the very particular risk assessments we need to make. While it is a good idea to contact one's national embassy upon arrival, it is important to be aware that the duties of embassy staff are (a) to maintain good relations with the host country and (b) to be responsible for their nationals when there is any kind of difficulty. Both of these roles may cause them to be conservative in their advice, and not overenthusiastic about political science research undertaken by their nationals. Just like the information from human rights NGOs, the advice from embassies should be seriously considered, but there are good reasons not to make it your primary behavioral guide (see also Loyle 2016, 928).

The best source of information for first-time visitors may be more experienced academics, especially those who have recently been in the field themselves. While some may display gatekeeper behavior, most will be encouraging and helpful. Loyle $(2016,929)$ also recommends 'works of fiction and journalistic non-fiction', and especially fiction by local authors. If they exist in a language accessible to you, such sources can be great for 
conveying a sense of the culture (including, sometimes, the political culture) you are about to enter. Of course, they should not usually be relied on for topical analysis of recent political developments.

Our Malaysia researcher initially overestimated the dangers of his field research, which involved interviews especially with social movement activists. Describing himself as 'starting from zero', he discussed the risks of this fieldwork with various social scientists and a human rights activist about before going. He asked them what with hindsight seemed to him naïve questions: are activist leaders known by name, can you openly e-mail them? Nonetheless, he soon discovered that in Malaysia too, there are limits to how openly one can investigate anti-government protest.

The Iran researcher's preparations were very much colored by the events that had occurred towards the end of his $\mathrm{PhD}$ research: many of the activists he had interviewed and befriended had been forced into exile after the failure of Iran's Green Movement. Moreover, he had not returned for five years and had published critically on Iran in western media in the meantime. The advice he received from Iranian contacts was ambiguous. He went ahead with his visit, which turned out to be not very dangerous, but not very productive either, as we will elaborate in later chapters.

Because of the heightened security concerns, our Mexico researcher proceeded with his research in stages: starting in the capital and taking time to take advice from a relevant human rights organization, before proceeding to the more risky subnational context of Veracruz. When he arrived, both the human rights organization in the capital and the local representative of an international security consultancy were aware of his whereabouts and the nature of his research. This did not guarantee that nothing would happen. But it did mean that if there were an arrest, a threat, an assault, the local actors with the most appropriate local expertise, and with at least some clout, could immediately be involved.

Our repeat visitors, now country experts, all prepare in similar ways: they read local news and keep up their network, speaking to local friends and colleagues on a regular basis. In this regard, there is not a clear distinction between continually updating their substantive knowledge of the political developments and assessing the risks associated with the next fieldwork trip. Even our China researcher, born and bred in China, constantly updates her sense of the trends and patterns in how much space there is for social scientists to do their work. She talks to trusted friends and colleagues on Chinese social media, practicing her interview questions and honing her sense of what can be said to whom. 


\section{Going the Anthropologist Way}

And yet, until you go you cannot really prepare. Our experience is that, for a first visit especially, it is best not to want too much, too soon. Take time to adjust to your environment. Read local papers; have some conversations with the proverbial taxi drivers. Take a language class. Exploratory talks are necessary, background conversations to orient oneself on what is safe for oneself and others. Visit your embassy, perhaps an international organization. Talk to some foreign journalists, some local academics.

More than in relatively democratic settings, authoritarian fieldwork requires caution, patience, and the willingness to accept that it is not always possible to interview those one wants to speak to, or ask them the questions one had planned to ask (see also Loyle 2016, 930-932; Malekzadeh 2016, 863-864; Markowitz 2016, 900-901 on creativity and flexibility in research design). The first few weeks, perhaps the entire first visit, may not yield immediate results. You have to go and see what is possible and slowly develop a plan to relate what you want to find out to what seems possible on the ground. In some contexts one can contact relative strangers via e-mail, but more often one depends on introductions from friends (see also Chap. 4). It is also important at this stage to shed assumptions that turn out to be oversimplifications, for instance, that demonstrations are either for or against the government, or that the general population is either apolitical or deeply political.

Generally, we try to keep multiple people aware of our whereabouts. Many of us have one or more trusted local contacts, who know what we are doing almost on a daily basis. We stay in frequent touch with parents or partners, and we make sure that people at home and in the fieldwork country have each other's contact details, so they can consult in case of an emergency. About once a week, we discuss our progress, strategy, and potential security risks, with a colleague at our home university.

\section{Encountering the Security Apparatus}

The need to take it slow, especially on a first visit, is illustrated by an early experience of our Malaysia researcher. In his first few days, he discovered that students or taxi drivers spoke much more openly about both the government and the main protest movement, Bersih, than he had expected. After five days in the country, an apparently golden opportunity fell into his lap: a protest was planned against a free trade agreement. Two local 
contacts thought it would probably be fine for him to attend the demonstration and talk to participants-although his own embassy advised against it. He prepared a short survey, online as well as on paper, and proceeded to the demonstration bright and early. After a brief chat with two youngsters who planned to demonstrate, he sat down on a bench with one of them and pulled his survey out. Within minutes, two bulky plainclothes security agents sat down next to him and demanded to see his papers. They asked whether he had a permit, told him repeatedly that they could not guarantee his security, demanded his passport and proceeded to photograph it. They then told him to go back to his hotel, where he stayed the rest of the day, abandoning his plans for the survey. Two reflections follow from this early encounter: if this protest had not come quite so soon after arrival, the researcher would probably have known to keep a lower profile during the demonstration. At the same time, he might have been less intimidated by the incident, and might have had the phone number of a lawyer on hand. On a repeat visit, he successfully attended a Bersih demonstration.

As a $\mathrm{PhD}$ student, our China researcher never considered what she might do if security agents would want to interview her. But as a postdoc in our project, after hearing that various Chinese scholars and some foreign scholars' Chinese students had been approached by the security services, for a 'cup of tea', she began to prepare, and make, a mental list of what to do in such a situation. Before the second fieldwork trip for our project, a Chinese colleague in China told her that he had been invited to meet two local security agents. After talking about his own research on China and the EU, they asked him questions about our funder, the ERC. According to the colleague, it was a civil meeting and he did not feel any sense of threat; they did not warn him or force him to do anything. The agents were curious about social science research in the west in general, but appeared to be to have two specific concerns. First, they wanted to understand whether the ERC was comparable to funding institutions (e.g. the Ford Foundation) that fund human rights activists and frequently touch the 'red lines' (see next chapter) of the Chinese government. Second, they wanted to understand the purpose and intentions of our project: why did we want to understand things about Chinese politics? Did we want to use our knowledge of China to instigate revolt against the Chinese Communist Party? Did we want to use the experience and lessons from the Arab spring and use social media for rebellion in China? It was clear that they were not worried about western social science research on 
China in general, but concerned about certain topics that might be funded by 'suspicious' sponsors or touching 'red lines'. Such a 'friendly visit' to a third party, indicating that a research project has somehow gotten onto the radar of the security services, appears to fit with the experience of some researchers in the post-Soviet sphere (Gentile 2013, 430) as well as Malekzadeh's experience in Iran $(2016,872)$.

We contacted our advisors and various China scholars, western and local. Their and our assessment was that the inquiry into our project did not constitute an unacceptable risk to our China researcher. We did, however, think through likely questions that security agents might ask. The answers, we agreed, should be truthful, but have an apolitical slant (see Chap. 3). Just as Gentile $(2013,430)$ advises, politeness and diplomacy should be observed as much as possible, and in the best case, an interview might actually present 'an opportunity to clarify possible misunderstandings'. Only the identity of our researcher's respondents, and details of what they said, should be sacrosanct. As it turned out, her fieldwork was entirely uneventful. She received no invitation and did not notice any surveillance or intrusion at all.

Some of the risky situations we have experienced are not directly but indirectly related to the authoritarian context. Our Iran researcher underwent an incident of attempted extortion (which we will detail in Chap. 5), the motive of which may just have been personal gain, but the act was committed by a person connected to a security agency. Such a person may have, or at least feel they have, a higher degree of impunity in engaging in such behavior. Likewise, the risk of sexual harassment is something familiar to any solo-traveling female, but may take on a more menacing aspect when the agent is a state official in an authoritarian context. Our Morocco researcher had such an experience. She was invited by an official to a formal dinner where she could meet many relevant contacts, but he refused to give her the name of the restaurant and insisted instead that she should meet him for a drink at his place. Our researcher resolved the dilemma by pretending to accept, but a few minutes before they were supposed to meet, calling him to say that a previous appointment had lasted longer than expected and that she was too far away to make it to his home. Thus the official had no choice than to pick her up where she was and go directly to the restaurant. During the dinner, the official kept on filling her glass. Understanding what was happening, she realized that the last thing she wanted was to find herself alone with him in his car. A good tip to the waiter made it possible to have a taxi ready for her in front of the restaurant. Thus when he offered her a 
lift, it took her only few seconds to politely refuse and jump into her waiting taxi. The incident illustrates the particular interface between gender-based and authoritarian risk that female researchers may face. When in doubt, it may be wisest to sacrifice a spontaneous research opportunity if there is a clear risk of harassment. The episode also suggests, however, that for a researcher familiar with the context, some skillful navigation can make it possible to grasp the opportunity whilst staying safe.

\section{Data Security Trade-Offs}

We do not know to what extent any of us are under electronic surveillance from security institutions from authoritarian or indeed democratic states. In Chap. 5 we discuss our actual experiences with electronic surveillance; here we describe our preparations for it. We take it as given that, as Gentile puts it ' $(w)$ hen doing fieldwork in countries ruled by authoritarian regimes it is possible that phone calls, emails and letters are monitored', and further assume that any online activity, or documents on online servers or in virtual clouds, may be subject to scrutiny. Our most elaborate fieldwork preparations as a group related to data security, in particular contact details of respondents and interview transcripts. Before our fieldwork, our project had organized a few digital security training sessions from an expert in this area. With hindsight though, we have come to second-guess some of our initial learnings from these sessions, which were very much inspired by a post-Snowden focus on digital surveillance and online intrusions at the expense of thinking through more traditional security threats and basic travel precautions. One common device we had agreed on was to take two laptops into the field: one for web browsing, e-mails, and so on and one secondhand laptop that never went online, but acted almost as a typewriter, for transcribing interviews. We would keep these separate from the actual contact details of these respondents.

We have found, however, that applying high levels of digital security also has disadvantages. Now, we tend to think data security more in terms of trade-offs. The first is that it is simply time-consuming and cumbersome. In Kazakhstan, our researcher initially used two computers and two phones, with three SIM cards. Both the China and the Malaysia researchers took no less than three laptops into the field, a heavy load. Transcribing interviews on an offline laptop protects respondents from electronic surveillance and would make their identity hard to detect, but of course it does not offer absolute security. It also increases the chances of losing transcripts. Indeed, our researcher in Gujarat, 
India had a terrible experience of this kind. Having done quite a few sensitive interviews with opponents of Narendra Modi, he had meticulously stuck to the strategy of keeping anonymized transcriptions only on the offline computer, and separately on USB sticks. On his trip back, transferring through Abu Dhabi airport, he kept both in his hand luggage. This bag was stolen-or possibly confiscated, we'll never knowduring baggage screening at the airport. It was never recovered.

Another trade-off is that extreme security measures can actually draw suspicion. If you behave like a spy or agent provocateur, you are more likely to be suspected of being one. Our general policy has been to rely on the notion, accepted in most but perhaps not all authoritarian contexts, that social science research is a legitimate enterprise (see also Chap. 3 ), and we engage in it openly, but we have a professional duty to protect our data, and usually also the identity of our respondents. Indeed, our Iran researcher was advised against bringing a second laptop because it might raise suspicion, and decided not to bring one. Likewise, our Kazakhstan researcher gave up using the second laptop after a while. She came to the conclusion that, given that her research topic was not particularly sensitive, the risk of raising red flags during passport control by having a second laptop actually outweighed the benefits of better protection from electronic surveillance. A final trade-off relates to how taking digital security measures makes us feel, an issue we will return to in Chap. 5. Precautionary routines may increase our sense of comfort during stressful fieldwork, but it can also end up making us feel unnecessarily paranoid.

The lengths we went to protect respondent identities and transcripts depended in part on the sensitivity of the questions we were asking, and in part on what was considered appropriate in the context. Our Kazakhstan researcher used pseudonyms for her interviews with students who had been on a state-sponsored study-abroad scheme, but did not encrypt them. In Kazakhstan, the use of encryption is subject to legal restrictions, and would immediately signal that one has something to hide. Moreover, some experts believe that the introduction of a mandatory 'national security certificate' for Internet users in 2015 has actually made encryption more vulnerable to surveillance by the security services. Since her respondents came from a relatively select group of people, she thinks that if somebody would have gotten hold of her computer, they would surely have found a way to connect transcripts to respondents. However, she did not ask particularly sensitive questions, so if a state agent had somehow come to read or listen to the interviews, respondents would still not have been endangered. In the case of Malaysia, many of the activists interviewed were well-known 
public figures, who were comfortable going on record with everything they said, so there was no reason to keep the transcripts concealed offline, or separate them from names and contact details.

Our Iran expert by contrast, who has also interviewed activists, has taught himself to routinely use encryption. When he first started doing research in 2008, he had concerns about his transcripts getting physically impounded. However, he did not know much about Internet surveillance at the time, and he would simply e-mail his transcripts to his partner back home before erasing them. In 2015, he erased all data from his laptop before traveling to Iran. Less sensitive interviews he kept on his laptop, a bit hidden away with nondescript file names, more sensitive ones he would encrypt.

Some of us never record interviews but rely exclusively on extensive notes. Notes, they say, can have the advantage of making respondents more comfortable but also of making the interviewer more attentive to what she is hearing. Others do use recordings, but not for the most sensitive issues. All of us make copious notes, often in a mix of languages and even scripts, which are not readily intelligible to others. In case of extremely sensitive confidential information, we sometimes write nothing down at all but try to commit it to memory. There is an obvious tension here, which we will revisit in Chap. 6, between accuracy and transparency on the one hand, and protecting ourselves and our respondents on the other hand.

We went through a learning curve, from having little awareness of data security issues to assuming that rigorous measures like the use of offline laptops and encryption provide the most safety to thinking in terms of trade-offs between greater digital security on the one hand and the risks of arousing suspicion, physical theft, or becoming caught up in paranoia on the other hand. Our general experience has been that it is worthwhile to learn and practice a range of digital security routines before going into the field, so that we know how to use them if we find that the context requires it. If we then find that the routines we had envisaged are unnecessary or even inappropriate, we can relax or abandon them. The other way around, ratcheting up one's digital security routines once in the field, could be technically and practically much more difficult.

\section{Chapter Conclusion: Planning Ahead AND AcCEPTING Risk}

Preparing as well as we can may improve our judgment when faced with a sensitive situation, and - not unimportantly — give us some peace of mind. Ethics procedures, when well designed, can actually help us prepare by 
pushing us to think about challenges we might face. We prepare in advance by reading up from various sources, and by talking to politically minded people who live in our fieldwork country, or have visited recently. Visa procedures sometimes give us our first taste of the vagaries of authoritarian bureaucracies. We should take some time to acclimatize on arrival, especially if it is a first visit, the situation has changed, or our topic is particularly sensitive. We scenario-plan how we might handle an encounter with security agents. We can develop and practice digital routines. But even for experienced country experts, or people who are nationals of the state they investigate, unexpected situations may come up, and there is no fail-safe way to prepare and to figure out exactly what is and is not dangerous for oneself and others. Having assessed and minimized our risk, we accept that it exists.

\section{REFERENCES}

Ahram, A. I., \& Goode, J. P. (2016). Researching Authoritarianism in the Discipline of Democracy. Social Science Quarterly, 97, 834-849. https://doi. org/10.1111/ssqu.12340.

Central Eurasian Studies Society (CESS). (2016, March 5). Taskforce on Fieldwork Safety. Final Report. Retrieved July 19, 2017, from http://www.centraleurasia. org/assets/site/cess-task-force-on-fieldwork-safety_final-report-march-2016.pdf.

Clark, J. (2006). Field Research Methods in the Middle East. PS: Political Science \& Politics, 39, 417-424. https://doi.org/10.1017/S1049096506060707.

Davenport, C., \& Stam, A. C. (2009, October 7). What Really Happened in Rwanda? Miller-McCune Research Essay. Retrieved June 20, 2017, from https://psmag.com/social-justice/what-really-happened-in-rwanda-3432.

Gentile, M. (2013). Meeting the 'Organs': the Tacit Dilemma of Field Research in Authoritarian States. Area, 45, 426-432. https://doi.org/10.1111/area.12030.

Gladstone, R. (2017, July 17). Colleagues of Princeton University Scholar Convicted of Spying in Iran Express Shock. New York Times.

Goode, J. P. (2010). Redefining Russia: Hybrid Regimes, Fieldwork, and Russian Politics. Perspectives on Politics, 8, 1055-1075. https://doi.org/10.1017/ S153759271000318X.

Goode, J. P. (2016). Eyes Wide Shut: Democratic Reversals, Scientific Closure, and the Study of Politics in Eurasia. Social Science Quarterly, 97, 876-893. https://doi.org/10.1111/ssqu.12343.

Goode, J. P., \& Ahram, A. I. (2016). Special Issue Editors' Introduction: Observing Autocracies from the Ground Floor. Social Science Quarterly, 97, 823-833. https://doi.org/10.1111/ssqu.12339.

Kassam, A. (2016, October 10). Canadian-Iranian Professor: I Survived Imprisonment by Studying my Captors. The Guardian. 
Loyle, C. E. (2016). Overcoming Research Obstacles in Hybrid Regimes: Lessons from Rwanda. Social Science Quarterly, 97, 923-935. https://doi. org/10.1111/ssqu.12346.

Malekzadeh, S. (2016). Paranoia and Perspective, or How I Learned to Stop Worrying and Start Loving Research in the Islamic Republic of Iran. Social Science Quarterly, 97, 862-875. https://doi.org/10.1111/ssqu.12342.

Markowitz, L. P. (2016). Scientific Closure and Research Strategies in Uzbekistan. Social Science Quarterly, 97, 894-908. https://doi.org/10.1111/ssqu.12344.

Matelski, M. (2014). On Sensitivity and Secrecy: How Foreign Researchers and Their Local Contacts in Myanmar Deal with Risk Under Authoritarian Rule. Journal of Burma Studies, 18, 59-82. https://doi.org/10.1353/jbs.2014.0008.

Pepinsky, T. (2017, January 6). Everyday Authoritarianism Is Boring and Tolerable. Retrieved July 21, 2017, from https://tompepinsky.com/2017/01/06/ everyday-authoritarianism-is-boring-and-tolerable/.

Schreck, C. (2015, March 31). Western Scholars Alarmed by Russian Deportations, Fines. Radio Free Europe/Radio Liberty. Retrieved June 15, 2017, from https://www.rferl.org/a/russia-western-scholars-alarmed-deportations/2692992 1.html.

Wall, C., \& Overton, J. (2006). Unethical Ethics?: Applying Research Ethics in Uzbekistan. Development in Practice, 16, 62-67. www.jstor.org/stable/4029860.

Open Access This chapter is licensed under the terms of the Creative Commons Attribution 4.0 International License (http://creativecommons.org/licenses/ by $/ 4.0 /$ ), which permits use, sharing, adaptation, distribution and reproduction in any medium or format, as long as you give appropriate credit to the original author(s) and the source, provide a link to the Creative Commons license and indicate if changes were made.

The images or other third party material in this chapter are included in the chapter's Creative Commons license, unless indicated otherwise in a credit line to the material. If material is not included in the chapter's Creative Commons license and your intended use is not permitted by statutory regulation or exceeds the permitted use, you will need to obtain permission directly from the copyright holder.

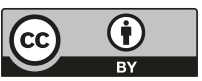

